\title{
A DIGNIDADE HUMANA COMO FUNDAMENTO ÉTICO LIBERTADOR A PARTIR DA RESISTÊNCIA E DA ALTERIDADE
}

\author{
HUMAN DIGNITY AS A RELEASE ETHICAL GROUND SINCE \\ RESISTANCE AND OTHERNESS
}

\author{
Karina Macedo Fernandes ${ }^{\mathrm{I}}$ (iD) \\ Raysa Antônia Alves Alves ${ }^{\mathrm{II}}$ (iD \\ Marcelo Andrade de Azambuja ${ }^{\text {III }}$ (iD
}

\begin{abstract}
${ }^{\text {I } U n i v e r s i d a d e ~ d o ~ V a l e ~ d o ~ R i o ~}$ dos Sinos (UNISINOS), São

Leopoldo, RS, Brasil. Doutora em Direito Público. E-mail: karimfernandes@gmail.com
\end{abstract}

II Universidade do Vale do Rio dos Sinos (UNISINOS), São

Leopoldo, RS, Brasil. Mestranda em Direito Público, como

bolsista PROEX/CAPES. E-mail: raysaantoniaalves@gmail.com

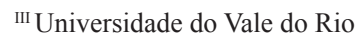
dos Sinos (UNISINOS), São

Leopoldo, RS, Brasil. Mestrando em Direito Público, como bolsista PROEX/CAPES. E-mail: ma.azambuja@hotmail.com

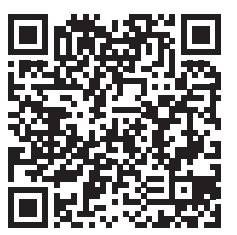

DOI: $10.20912 /$ rdc.v15i36.35
Resumo: O presente artigo objetiva demonstrar em que medida as contribuições kantianas para o Direito, a partir da ideia de moralidade e de dignidade, podem contribuir para a construção de um espaço crítico de fundamentação ética e de contestação ao discurso hegemônico dos direitos humanos. A partir de então, acredita-se ser possível apontar modos pelos quais a alteridade e na resistência podem consistir numa práxis libertadora, exercitada a partir de um enfoque cultural e corporal dos direitos humanos, que visem tanto o eu como o Outro como um fim.

Palavras-chave: Dignidade humana. Direitos Humanos. Alteridade. Teoria Crítica dos Direitos Humanos. Pensamento Descolonial.

Abstract: This article aims to demonstrate the extent the Kantian contributions to the Law, from the idea of morality and dignity, can contribute to the construction of a ethical foundation's critical space and a contestation to the human rights' hegemonic. Since then, it is believed in the possibility to indicate ways in which otherness and resistance can consist of a liberating praxis, exercised from a cultural and corporal approach to human rights, which views both self and Other as an end.

Keywords: Human dignity. Human rights. Otherness. Critical human rights studies. Decolonial thought.

Recebido em: 26.06.2019

Aceito em: 28.10.2019 


\section{Introdução}

De acordo com o pensamento filosófico moderno, expresso, sobretudo, em Kant, a dignidade do ser humano é um valor absoluto determinado pela racionalidade que estes têm em comum, valor este que fundamenta a moralidade ou que torna os seres humanos um fim em si mesmo ${ }^{1}$. Considerando que o principal fundamento dos direitos humanos, encontra suas raízes no valor da pessoa e da dignidade humana, este trabalho pretende demonstrar em que medida as contribuições kantianas para o Direito, a partir da ideia de moralidade e de dignidade, podem contribuir para a construção de um espaço crítico de fundamentação ética e de contestação do discurso hegemônico dos direitos humanos.

Tendo em vista que, em Kant, a autonomia que é inerente à moralidade, para Kant, busca-se esclarecer as insuficiências da doutrina kantiana para a atribuição de dignidade a todos os seres, apresentando, inicialmente, os principais contributos de Kant à formação desse discurso. Em um segundo momento, serão abordadas algumas críticas à matriz teórica kantiana e à modernidade encobridora das subjetividades, de maneira que serão trazidos alguns aportes teóricos para a consideração da dignidade humana enquanto fundamento dos direitos humanos a partir da ideia libertadora da alteridade.

Os referenciais teóricos adotados são do pensamento descolonial e da teoria crítica dos direitos humanos, estudos que se mostram capaz de viabilizar um saber estratégico dos direitos humanos, que incremente argumentos para atuar e gerar disposições críticas e antagonistas em face da estrutura ou da ordem social hegemônica, viabilizando suas propostas de realização como fim e além das utopias historicamente apresentadas nesse sentido.

1 KANT, Immanuel. Fundamentação à Metafísica dos Costumes. São Paulo: Companhia Editora Nacional, 1964. 


\section{A moralidade e a racionalidade como determinantes da dignidade e da fundamentação dos Direitos Humanos}

No pensamento filosófico kantiano, a dignidade do ser humano é um valor absoluto determinado pela racionalidade que estes têm em comum, valor este que fundamenta a moralidade ou que torna o ser humano um fim em si mesmo. Nesse sentido, Kant defende que a lei moral define o bem e o mal, de maneira que as pré-condições universais da ação moral são descobertas na ação livre e racional, que segue a lei do imperativo categórico "procede apenas segundo aquela máxima, em virtude da qual podes querer ao mesmo tempo que ela se torne lei universal"2. Isso significa dizer que se houver a necessidade de se realizar uma escolha moral, deve-se proceder de acordo com o que seja universalmente aplicável sem contradição a todas as situações similares. O Direito, portanto, é compreendido no sentido moral, de justo e injusto. O conceito moral de direito refere-se a uma obrigatoriedade, que significa "a necessidade de uma ação livre sob um imperativo categórico da razão". Logo, a Kant trata do imperativo categórico do direito no singular, do conceito e padrão de medida do direito ordenado moralmente ${ }^{3}$.

A racionalidade, dessa forma, torna-se uma exigência no sistema kantiano para que se estabeleçam condições de moralidade, uma vez que somente assim as leis morais poderão ter o valor de universalidade ${ }^{4}$. De acordo com Kant, todo ser racional, enquanto fim em si mesmo, deve poder se considerar, com respeito a quaisquer leis a que possa estar submetido, ao mesmo tempo como legislando universalmente, porque é exatamente essa conveniência de suas máximas para a legislação

2 KANT, Immanuel. Fundamentação à Metafísica dos Costumes. São Paulo: Companhia Editora Nacional, 1964, p. 83.

3 HÖFFE, Otfried. O imperativo categórico do Direito: uma interpretação da "Introdução à Doutrina do Direito". Studia Kantiana, v. 1, n. 1, 1998. p. 206.

4 BARRETTO, Vicente de Paulo. O Fetiche dos Direitos Humanos e outros Temas. 2. ed. Porto Alegre: Livraria do Advogado, 2013, p. 71. 
universal que o distingue como um fim em si mesmo ${ }^{5}$; do mesmo modo, segue-se daí, também, que a dignidade deste diante de todos os seres meramente naturais implica que ele tenha de tomar as suas máximas sempre do ponto de vista de si mesmo, mas, ao mesmo tempo, do ponto de vista de todo outro ser racional enquanto legislante, os quais por isso mesmo também se chamam pessoas.

Somente assim é possível um mundo de seres racionais como um reino dos fins, isso pela própria legislação de todas as pessoas enquanto membros. Consequentemente, todo ser racional deve agir como se fosse sempre, através de suas máximas, um membro legislador do reino universal dos fins. Reino, para Kant, significa a união sistemática de diversos seres racionais por meio de leis comuns, de maneira que estes mesmos seres racionais estão sujeitos à lei, em virtude da qual cada um deles nunca deve tratar a si e aos outros como puros meios, mas sempre e simultaneamente como fins em si ${ }^{6}$.

Com isso, pode-se dizer com Kant que a moralidade consiste na relação de todas as ações (racionais) com a lei, e que somente esta moralidade possibilita um reino dos fins. Em outras palavras, todo ser racional deve poder emanar a sua vontade segundo a máxima que possa ser erigida a lei universal: "que a vontade possa, mercê de sua máxima, considerar-se como promulgadora, ao mesmo tempo, de uma legislação universal" ". A relação de vontade de todo ser racional deve sempre ser considerada como legisladora, porque somente assim pode ser concebida como fim em si. Para Kant:

“[...] A razão refere assim toda máxima da vontade concebida como legisladora universal, a toda outra vontade, e também a toda ação que o homem ponha para consigo: procede assim, não tendo em vista qualquer outro motivo prático ou vantagem futura, mas levada pela ideia de dignidade de um ser racional

5 KANT. [1964]. Op cit., p. 90-91.

6 KANT. [1964]. Op cit., p. 96.

7 KANT. [1964]. Op cit., p. 97. 
que não obedece a nenhuma outra lei que não seja ao mesmo tempo instituída por ele próprio"s.

A moralidade é, dessa forma, a única condição que possibilita ao ser racional participar na legislação universal como membro do reino dos fins, e, junto à humanidade (enquanto capaz de moralidade) é das "únicas coisas que possuem dignidade". A legislação, nesse sentido, deve ser dotada de moralidade para que possa ser considerada digna, ou seja, um valor incondicional, que só pode ser adjetivado justamente pelo termo respeito. Com isso, Kant define que a autonomia é o princípio da dignidade da natureza humana ou de toda natureza racional ${ }^{10}$, uma vez que a moralidade é a relação das ações com a autonomia da vontade, ou com a legislação universal que as máximas da vontade devem tornar possível.

O conceito de liberdade é chave no pensamento kantiano e com ele se pode chegar à definição de dignidade humana. Kant considera que o homem como pertencente ao mundo inteligível somente pode considerar o exercício de sua vontade sob o signo da liberdade, independente, portanto, das causas determinantes do mundo sensível. Vicente Barretto pontua que, para Kant, "a ideia da liberdade está inseparavelmente ligada ao conceito de autonomia, e a este o princípio universal da moralidade, o qual na ideia está a base de todas as ações de seres racionais como a lei natural está na base de todos os fenômenos" ${ }^{11}$.

$\mathrm{Na}$ segunda parte da Fundamentação da Metafísica dos Costumes, Kant indica a necessidade da filosofia prática como ponto fundamental para a construção de uma moral, que deve se originar e residir na razão. Para tanto, é necessário seguir e descrever claramente a faculdade prática da razão, partindo de suas regras universais de determinação até o ponto em que dela nasce o conceito de dever:

8 KANT. [1964]. Op cit., p. 97-98

9 KANT. [1964]. Op cit., p. 98.

10 KANT. [1964]. Op cit., p. 99.

11 BARRETTO, Vicente de Paulo. O Fetiche dos Direitos Humanos e outros Temas. 2. ed. Porto Alegre: Livraria do Advogado, 2013, p. 75. 
A vontade absolutamente boa, cujo princípio deve ser um imperativo categórico, será, pois, indeterminada a respeito de todos os objetos, e não contém senão a forma do dever em geral, e isto como autonomia; quer dizer que a aptidão da máxima de toda boa vontade para se arvorar em lei universal é a única lei que a vontade de todo ser racional se impõe a si própria, sem lhe acrescentar qualquer princípio oriundo de inclinação ou interesse (KANT, 1964, p. 108-109).

Além da Metafisica dos Costumes, podem se encontrar contribuições kantianas para o direito na Doutrina da Virtude, quando Kant afirma que no sistema da natureza, o homem (homo phaenomenon) possui menor importância se comparado a outros animais, enquanto que se for considerado como pessoa ou como sujeito de uma razão moralmente prática, encontra-se acima de qualquer preço; seria a partir daí que o ser humano não poderia ser considerado unicamente como um meio para os fins próprios ou alheios, mas sim como um fim em si mesmo. Isso quer dizer que todo ser humano racional possui uma dignidade enquanto, como definido na Metafísica dos Costumes, um valor interior absoluto, através do qual ele obriga o respeito de si mesmo por todas as outras criaturas da espécie e de se considerar em pé de igualdade ${ }^{12}$.

Kant considera a dignidade como o traço distintivo da pessoa em relação aos demais seres vivos. Dessa forma, enquanto no texto da Doutrina da Virtude atribui um estatuto valorativo à pessoa, onde considera o ser humano como um agente moral, um ser dotado de autonomia e, por essa razão, em situação hierárquica superior aos demais seres criados ${ }^{13}$, na Fundamentação da Metafísica dos Costumes, acentua que a moralidade é a única condição sob a qual um ser racional pode ser fim em si mesmo, porque somente através dela é possível ser um membro legislante no reino dos fins.

12 BARRETTO, Vicente de Paulo. O Fetiche dos Direitos Humanos e outros Temas. 2. ed. Porto Alegre: Livraria do Advogado, 2013, p. 71.

13 BARRETTO. [2013]. Op cit., p. 71. 
Através da base da racionalidade, Kant estabelece a condição inicial para que se possa desenvolver o conceito de homo noumenon, expressão, criada pelo próprio Kant que se origina da distinção entre o mundo sensível e o mundo da razão ou inteligível. No mundo inteligível, o homem se distancia dos demais seres, justamente por ser dotado de razão, o que o torna um noumeno, uma coisa em si mesmo. Kant, no seu segundo passo em direção à conceituação de dignidade humana, sustenta que ser humano é algo em si mesmo ${ }^{14}$.

Como destinatária de direitos, deveres e responsabilidades, a pessoa humana é conceituada por Kant a partir de Boécio como sendo o indivíduo cujas ações estão sujeitas à imputação, de modo que o ser racional tem a liberdade de obedecer às leis morais ${ }^{15}$, as quais possuem como fundamento o próprio homem como fim em si mesmo. Assim, a ideia de dignidade necessariamente está ligada à concepção de pessoa, do que emerge uma série de problemas, sobretudo de ordem antropológica, uma vez que a dignidade, para Kant, não se dirige indistintamente a todos os seres humanos.

Todavia, sendo a dignidade um respeito que se deve a si mesmo, ancorado na ideia de moralidade, cabe trazer à tona que Kant trata do conceito moral de direito como sinônimo de justiça ${ }^{16}$, de maneira que os homens, enquanto pessoas, devem se reconhecer reciprocamente como parceiros naturais de direito. Por essa razão é que ninguém pode se submeter voluntariamente à violência ou desrespeitar-se; esse é o sentido, também, do absolutismo do conceito, na fundamentação do fim de quaisquer práticas e condutas que possam ser consideradas degradantes à pessoa humana.

A dignidade humana suscita, com isso, o questionamento: como conciliar a liberdade individual e o imperativo categórico da moralidade

14 BARRETTO. [2013]. Op cit., p. 71-72.

15 KANT, Immanuel. Doutrina do Direito. São Paulo: Ícone, 1993, p. 42.

16 HÖFFE, Otfried. O imperativo categórico do Direito: uma interpretação da "Introdução à Doutrina do Direito". Studia Kantiana, v. 1, 1998. p. 213217. 
que afirma a autonomia dessa liberdade como o princípio fundamental da dignidade?

Ao trabalhar com a relação social que desafia o direito (ou a relação social inevitável), Kant afirma três condições de aplicação do conceito moral de direito: intersubjetividade na reciprocidade, ou na influência de uma pessoa sobre outra, através de um liberalismo responsável que será concretizado por meio da virtude; nesse ponto, Kant aborda especialmente da questão da liberdade de ação subsumindo os desejos internos, dentre os quais, a satisfação ou a felicidade do homem ${ }^{17}$.

Possivelmente, a regulação absoluta da vida humana, e consequentemente dos direitos humanos, pelo princípio da dignidade enseje necessariamente uma complementação à doutrina kantiana, no sentido de uma concretude material da dignidade da pessoa humana ou da ampliação das possibilidades de se fazer frente às tantas opressões que se verificam em detrimento dessa dignidade, numa práxis libertadora fundamental que considere a necessidade da constante adequação lógico-racional do princípio da dignidade humana a cada caso, "retirando o mesmo do invólucro adjetivo em que foi envolvido pela prática jurídica"18.

Inicialmente a partir da distinção entre pessoa e ser humano, deve se interpretar a teoria kantiana da moralidade como fundamento da dignidade a partir do imperativo categórico prático "procede de maneira que trates a humanidade, tanto na tua pessoa como na pessoa de toso os outros, sempre ao mesmo tempo como fim e nunca como puro meio"19. Portanto, ao ver a humanidade como fim em si é possível chegar a uma razão pura que coadune com o fundamento da dignidade também enquanto fim.

17 HÖFFE. [1998]. Op cit., p. 217.

18 BARRETTO, Vicente de Paulo. O Fetiche dos Direitos Humanos e outros Temas. 2. ed. Porto Alegre: Livraria do Advogado, 2013, p. 76-77.

19 KANT, Immanuel. Fundamentação à metafísica dos costumes. São Paulo: Companhia Editora Nacional, 1964, p. 92. 
Ao refletir sobre a teoria dos direitos humanos, seu caráter universal e sua concepção na contemporaneidade, imperioso se mostra visualizar sua fundamentação ética enquanto aspecto inerentemente relacionado ao plano da eficácia dos mecanismos garantidores do sistema dos direitos humanos ${ }^{20}$. Nesse sentido, considera-se que o fundamento racional maior para a consagração - e posterior positivação, evidentemente $^{21}$ - reside na própria ideia de dignidade humana, ou seja, na categoria moral e jurídica que qualifica, como característica central, as capacidades peculiares a todos os seres humanos.

A dignidade fundamentada na concepção kantiana, que entende o ser humano como um fim em si mesmo, pode ser percebida como uma qualidade intrínseca e indissociável de todo ser humano, que leva à realização da moralidade ${ }^{22} \mathrm{e}$, consequentemente, do respeito mútuo. Considerar sua fundamentação racional implica em considerar um dos principais eixos da identidade humana, tendo em vista que os "laços de solidariedade, fundados nos valores morais, representam a condição de sobrevivência do ser humano"23. Nesse ponto, é possível concluir que a proteção à dignidade da pessoa humana constitui em meta jurídica e estatal ampla e permanentemente afirmada, uma vez que constitui o eixo (tenso e) basilar de referência dos direitos humanos, sendo estes responsáveis por, designadamente, "abrigar e proteger a existência e o exercício das diferentes capacidades do ser humano"24.

A proteção da dignidade da pessoa humana condiz diretamente à moral jurídica universalista que legitima e conduz à positivação

20 BARRETTO, Vicente de Paulo. Multiculturalismo e direitos humanos: um conflito insolúvel? In: BALDI, César Augusto (Org.). Direitos humanos na sociedade cosmopolita. Rio de Janeiro: Renovar, 2004, p. 462.

21 BRAGATO, Fernanda Frizzo. Positivação e efetividade dos direitos humanos. Estudos Jurídicos. Universidade do Vale do Rio dos Sinos. São Leopoldo, v. 40, jul-dez 2007, n. 2, p. 67.

22 JUNGES, José Roque. A concepção kantiana de dignidade humana. Estudos Jurídicos. Universidade do Vale do Rio dos Sinos. São Leopoldo, v. 40, jul-dez 2007, n. 2, p. 86.

23 BARRETTO. [2004]. Op cit., p. 474.

24 BARRETTO. [2004]. Op cit., p. 475. 
de direitos a serem garantidos por certa comunidade política aos seus cidadãos ${ }^{25}$. Essa proteção ética, que constitui aspecto basilar da fundamentação e da eficácia na positivação dos direitos humanos, condiz à proteção das identidades intersubjetivas, à consagração de direitos individuais fundamentalmente objetivados por quaisquer contextos sociais. Jürgen Habermas sustenta, nesse sentido, que todas as pessoas se tornam individualizadas "apenas através de um processo de individualização"26, concluindo pela necessidade do reconhecimento das diversas moralidades expressas pelo multiculturalismo na concretização de direitos reconhecidamente fundamentais.

Conforme esclarece Fernanda Bragato, a efetividade dos direitos humanos, em razão da índole moral e pré-estatal desses direitos, não pode decorrer tão somente da sua positivação. Logo, o fundamento ético e moral que confere sentido aos direitos humanos e, além disso, legitima as leis que os consagram ${ }^{27}$ reside nos valores axiológicos expressos na concepção de dignidade humana,. É no reconhecimento do Outro ${ }^{28}$, na plenitude de sua dignidade individual, que reside o cerne das exigências morais que levam à expressão normativa caracterizadora dos direitos humanos ${ }^{29}$.

Todavia, considerando a dignidade um valor pautado na moralidade que fundamenta a legitimidade e, consequentemente, a defesa e a propagação dos direitos humanos, leva ao embate relacionado

25 BRAGATO. [2007]. Op cit., p. 67-68.

26 HABERMAS, Jürgen. A Ética da Discussão e a Questão da Verdade. São Paulo: Martins Fontes, 2007, p. 131.

27 BRAGATO, Fernanda Frizzo. Positivação e efetividade dos direitos humanos. Estudos Jurídicos. Universidade do Vale do Rio dos Sinos. São Leopoldo, v. 40, jul-dez 2007, n. 2, p. 69.

28 O Outro é aqui considerado no sentido de alteridade suscitado por Emmanuel Levinas e por Enrique Dussel, o qual vai além das concepções epistêmicas marginalizadas de alteridade da metafísica moderna. Parte, pois, do pressuposto que o $e u$ existe somente a partir do outro; que a relação do eu com o outro é que vai constituir a subjetividade e que, portanto, a alteridade é, além de uma categoria ética transcendental, condição do ser (LEVINAS, Emmanuel. Totalidade e infinito. Lisboa: Edições 70, 1980, p. 62).

29 BRAGATO. [2007]. Op cit., p. 70. 
à universalidade dos direitos humanos: a diversidade de moralidades e sistemas jurídicos, expressa pelo pluralismo cultural empiricamente constatado não seria um óbice ao caráter universal dos direitos humanos? A priori, entende-se que não. $\mathrm{O}$ reducionismo do universalismo dos direitos humanos às divergências trazidas pelo relativismo se traduzem numa "leitura simplificada da questão"30.

Entretanto, tem-se consciência de que, apesar de a dignidade humana ser amplamente vista como um valor intrínseco ao ser humano, a dificuldade maior reside nas formas pelas quais pode ser violada, porquanto, como já dito, os valores éticos e morais que a definem se manifestam diversamente a partir da multiplicidade de culturas e sistemas jurídicos. A partir daí, o espaço que se abre ao diálogo entre culturas constitui em uma das respostas plausíveis ao fundamento da dignidade da pessoa humana. A universalização, a partir do critério racional de viabilização da dignidade humana, é argumento potencialmente utilizado no confronto entre distintas e, até mesmo, questionáveis práticas culturais. Em virtude disso é que se propõe analisar um pouco mais este critério de fundamentação ética dos direitos humanos.

Portanto, o imperativo categórico kantiano pode apontar uma saída para a questão da universalização dos direitos, justamente porque questiona a atitude de cada um, quando se propõe a fazer alguma coisa, ou seja, se essa atitude poderia ser universalizada como máxima. Portanto a pergunta "o que fazer?" não leva a uma resposta totalitária, mas o conteúdo deve ser analisado caso a caso para casa pessoa. Nesse sentido, isso levaria a os sujeitos morais a reconhecer uns aos outros nessa atitude de perguntar a si mesmo se poderia ser universalizada essa tomada de decisão.

A universalidade é assim concebida por ser uma característica inerente à própria Declaração Universal dos Direitos Humanos, que clama por essa extensão universal dos direitos humanos sob a crença

30 BARRETTO, Vicente de Paulo. O Fetiche dos Direitos Humanos e outros Temas. 2. ed. Porto Alegre: Livraria do Advogado, 2013, p. 283. 
de que a condição de pessoa é o requisito único para a dignidade e titularidade de direitos. Nesse compasso se mostra a pertinência da crítica que François Jullien faz acerca da universalidade dos direitos humanos versada na Declaração Universal de 1948. Diz o autor:

[...] quando nos referimos, por exemplo, à Declaração universal dos direitos do homem, que tem valor de Manifesto sob esse aspecto, vemos claramente que "universal" não pode significar apenas, nesse caso, num sentido fraco, que se estende por toda a superfície da Terra, concernindo, em virtude disso, a todos os homens e todos os países (tal como falamos de 'Exposição universal', ou de geografia ou história universais). E isso, ainda que seja verdade que há um século, graças ao desenvolvimento das técnicas, com o fim das grandes explorações e sob o impulso do colonialismo, a história do 'mundo finito' começou e o globo é, enfim, percorrido em todos os sentidos: todos os territórios já foram sistematicamente abordados e passados no pente-fino a partir do epicentro europeu e a 'família humana' à qual tal Declaração se dirige acha-se finalmente completa. Pois aqui, "universal" não significa apenas essa extensão máxima, de natureza empírica, em suma, uma planetarização qualquer, mas, decerto, implica uma prescrição. Ou pelo menos a subentende: uma universalidade forte, fundada numa necessidade de princípio, logo, de natureza lógica, justifica sua concepção, ainda que a ambiguidade do texto a esse respeito não esteja completamente suprimida. Daí o mal-estar. Pois essa Declaração carrega consigo, nem que seja pelo que esse 'declarar' atribui-se de legitimidade, a invocação de um deverser. $^{31}$

Para Jullien, o caráter universalista da DUDH condiz à lógica homogeneizante herdada do eurocentrismo moderno, uma vez que o uniforme carrega consigo uma aspiração ao "um": enquanto o universal é 'voltado' para o Um-uni-versus - e traduz uma aspiração a seu respeito, o uniforme não é, desse um, senão uma repetição estéril. Para ele, a própria natureza desse 'um', “descambou" completamente de um para o outro, o qual não é mais o $U m$ eminente no qual o espírito se converte para sair da dispersão do diverso (do di-versus), mas o um reduzido, completamente amortecido, árido, da regularidade conformista e da

31 JULLIEN, François. O Diálogo entre as Culturas: do universal ao multiculturalismo. Trad.: André Telles. Rio de Janeiro: Zahar, 2009, p. 22. 
série, que "já não passa do retorno indefinido do mesmo e se espalha com tanto mais facilidade - prolificamente -, na medida em que, ao contrário do outro, não tem nenhuma preocupação com seu fundamento" ${ }^{2}$. Para François Jullien, isso repercute diretamente na inversão do universal à comodidade do uniforme, repetido, padronizado, descontextualizado.

$\mathrm{O}$ autor entende que os direitos humanos devem ser comuns a todos os seres humanos, e não universais, homogêneos, únicos. Somente o comum é que traz o consenso entre todos os seres humanos e permite que todos se sintam titulares de determinados direitos. Afirma, nesse sentido, que o conceito de comum "não é lógico (ou derivado da razão) como o universal, tampouco econômico (ou derivado da produção) como o uniforme, mas que, em sua essência, é político: o comum é aquilo de que temos parte ou tomamos parte, que é partilhado e do qual participamos"33. Em outras palavras, a universalização dos direitos humanos estaria caracterizada no diálogo intercultural, no compartilhamento de determinados valores parajurídicos, que perpassam qualquer ordem normativa ou sistema jurídico contemporâneo e dialoga com os interesses de cada um, dentro da pluralidade e da diversidade da sociedade.

Como concretizar, portanto, a dignidade fundamentadora dos direitos humanos sob a perspectiva do Outro? Essa é uma pergunta de difícil resposta e que encontra os seus problemas desde as diversas interpretações modernas da concepção kantiana de moralidade, assim como no discurso hegemônico dos direitos humanos, forjado a partir da modernidade.

32 JULLIEN. [2009]. Op. Cit., p. 29.

33 JULLIEN, François. O Diálogo entre as Culturas: do universal ao multiculturalismo. Trad.: André Telles. Rio de Janeiro: Zahar, 2009, p. 36. 


\section{Contestações à doutrina kantiana e aportes teóricos para a concretização da ideia de dignidade na fundamentação dos Direitos Humanos}

Considerando todas as fundamentações e investigações que abordam as doutrinas éticas tradicionais como necessariamente relacionadas a reflexões e análises, especialmente por serem concebidas como certas no período da Modernidade, um crítico dos imperativos categóricos de Kant e do imediatismo (antropo)egocêntrico das concepções éticas tradicionais, sobretudo diante das novas dimensões do agir coletivo é Hans Jonas, para quem "é central considerar a emergência de uma ética que garanta a existência humana e de todas as formas de vida existentes na biosfera" ${ }^{34}$. Hans Jonas propõe, assim, o Princípio Responsabilidade, como sendo um princípio ético para a civilização tecnológica, partindo da tese que alerta ter sido a promessa da tecnologia moderna convertida em ameaça, ou esta se associou àquela de forma indissolúvel ${ }^{35}$.

Jonas diz que a ética tradicional não é capaz de instruir sobre o bem e o mal, sendo incapaz de compreender as novas modalidades do poder, que, ante a este avanço tecnológico, são ainda enigmáticas. Dessa forma, há um vácuo que se relaciona com a questão do relativismo e que tangencia os postulados éticos no contexto contemporâneo, o qual, para Jonas, é aprioristicamente suprimido pela previsão do perigo que determina os princípios éticos que culminarão nas novas obrigações do novo poder. A isto, o autor chama de "heurística do medo"36. É

34 BATTESTIN, Cláudia; GHIGGI, Gomercindo. O Princípio Responsabilidade de Hans Jonas: um princípio ético para os novos tempos. Thaumazein, Santa Maria, out. 2010, n. 6, p. 72-74.

35 JONAS, Hans. O Princípio Responsabilidade. Ensaio de uma ética para a civilização tecnológica. Trad. Marijane Lisboa e Luiz Barros Montez. Rio de Janeiro: Contraponto, 2006, p. 21.

36 JONAS, Hans. O Princípio Responsabilidade. Ensaio de uma ética para a civilização tecnológica. Trad. Marijane Lisboa e Luiz Barros Montez. Rio de Janeiro: Contraponto, 2006, p. 21. 
justamente no antever o futuro e as repercussões que dele se sucederão é que se torna possível e viável pensar numa verdadeira ética do respeito.

Os postulados éticos ancorados na heurística do medo se justificam pela extensão metafísica que possuem, uma vez que somente a metafísica enseja o questionamento do porquê da existência humana e o porquê de lhe dever ser assegurada a existência futura. Em vista disso, o autor pretende sempre retomar as categorias principais da filosofia moderna que levou às renúncias da filosofia contemporânea, problematizando "as antigas questões sobre a relação entre ser e dever, causa e finalidade, natureza e valor, de modo a fundamentar no Ser, para além do subjetivismo dos valores, esse novo dever do homem, que acaba de surgir" ${ }^{37}$.

$\mathrm{O}$ antropocentrismo enraizado na doutrina de Kant foi a base de justificação do individualismo emergido nas teorias contratualistas da modernidade, sobretudo através de John Locke, as quais definem o modo de conceber o homem centrado na figura do indivíduo que se caracteriza como uma unidade referencial básica da sociedade. $\mathrm{O}$ discurso é da valorização do indivíduo e sua supremacia frente ao grupo e aos demais, a partir da aceitação de um conjunto de valores inerentes à natureza humana, identificados no princípio da dignidade humana ${ }^{38}$. A racionalidade é um pressuposto desta concepção, uma vez que nesse racional antropocentrismo, o homem assimilou sua capacidade de conhecer a si e os objetos, distinguindo e os dominando, decorrendo daí uma postura de valorização da liberdade, da autoconfiança, da privacidade, da autodeterminação e da autonomia.

37 JONAS. [2006]. Op cit., p. 22.

38 Nesse sentido, Richard Rorty, no texto "Human Rights, Rationality, and Sentimentality" (2001), explica como o antropocentrismo ou a concepção central de indivíduo levou às opressões entre homens e não humanos, entre homens e mulheres, entre adultos e crianças, o que leva à concepção de que há um padrão de ser humano formado pela racionalidade que rejeita tudo o que não se encaixe nos seus limites. (RORTY, Richard. Human rights, rationality and sentimentality. In: HEYDEN, Patrick. The politics of human rights. St. Paul, MN: Paragon House, 2001. p. 67-83). 
Portanto, muito embora Hans Jonas advogue a ideia de que a libertação do antropocentrismo pode ressignificar a ética tradicional através da possibilidade de existir um direito moral próprio da natureza e de alterar substancialmente os postulados éticos que reconhecem os "fins em si", ampliando-os a quaisquer esferas extra-humanas, entendese que suas críticas podem ser construtivas também ao campo da teoria e da fundamentação dos direitos humanos, especialmente porque tal ressignificação filosófica implica no questionamento de algumas das premissas da modernidade que levaram, necessariamente, à opressão e exclusão de uma série de direitos e grupos de pessoas.

Outro crítico à concepção racionalista dos direitos é Costas Douzinas (2009), para quem tal ideia torna a formulação dos direitos abstrata e generalizada, a ponto de torná-los irreais e não factíveis, inoperáveis ou "com os fins sendo sua imperfeição prática"39. O autor critica a formulação metafísica do direito na medida em que esta necessariamente leva à sua falsidade moral e inutilidade política ${ }^{40}$.

Amparado na crítica clássica do historicismo dos direitos de Burke, Costas Douzinas afirma que o racionalismo e a abstração dos direitos os transformam em princípios morais absolutos, contra os quais "não há remédios" ${ }^{41}$, considerando que direitos absolutos ignoram que diferentes sociedades conduzem a diferentes arranjos institucionais. Assim, Costas Douzinas afirma que, não obstante tenha sido seguido por muitos teóricos liberais, renegaram a crítica historicista da racionalidade e a necessidade de uma construção histórica do direito, mesmo sendo este imanente ao Estado: "nenhum legislador sábio pode construir a melhor república; isso vem com a imitação da natureza, 'em uma ampla duração de tempo e por uma grande variedade de acidentes"'42.

39 COSTAS DOUZINAS. O fim dos direitos humanos. São Leopoldo: Editora Unisinos, 2009, p. 164.

40 COSTAS DOUZINAS. [2009]. Op cit., p. 164.

41 COSTAS DOUZINAS. [2009]. Op cit., p. 167.

42 COSTAS DOUZINAS. [2009]. Op cit., p. 167. 
De outro lado, sob a perspectiva marxista, Costas Douzinas direciona-se à crítica à abstração do sujeito de direitos e à metafísica da moralidade ao afirmar que, sendo os direitos do homem a ideologia predominante da revolução, há que se atentar que tais direitos condizem ao homem universal abstrato, promovendo, na prática, os interesses de uma pessoa muito concreta, o indivíduo egoísta e possessivo do capitalismo ${ }^{43}$. Nessa concepção, é possível visualizar que, não obstante o fundamento da dignidade, o sujeito dos direitos humanos perde sua identidade concreta, com sua classe, seu gênero e suas características étnicas, visto que todas as determinações humanas reais se tornam sujeitas (ou submissas) ao poder do homem abstrato, sem história nem contexto, o que possibilitou a criação do antropocentrismo eurocêntrico ${ }^{44}$, em que os beneficiados são tão somente os membros da sociedade burguesa, ou seja, o homem egoísta e proprietário, isolado do Outro e da comunidade.

Costas Douzinas alerta que a dignidade humana deve ser necessariamente relacionada à felicidade, uma vez que aquela se torna impossível sem a concretização desta. E a felicidade, por sua vez, também não se concretiza jamais diante de quaisquer formas de

43 COSTAS DOUZINAS. [2009]. Op cit., p. 170.

44 Categorizando a modernidade como existente somente a partir do momento em que a Europa se autoafirma como o centro da história mundial que ela própria inaugura, tornando periférico tudo o que está fora dos seus limites, Enrique Dussel é um dos principais autores a analisar a experiência latino-americana como possibilitadora da Modernidade, a partir da Conquista, em 1492. Dussel defende que o conceito emancipador de modernidade preconizado por Hegel, Kant e, mais recentemente, Habermas, na verdade, encobre um mito, legitimado pelo eurocentrismo e pela falácia desenvolvimentista. O mito a que Dussel se refere é o da violência sacrificial, que, por sua vez, também marca a origem de um processo de ocultamento e de nãoreconhecimento do não-europeu e, consequentemente, de quaisquer identidades e subjetividades assim consideradas periféricas. Para Dussel, a construção das figuras abstratas do processo de constituição da subjetividade moderna, do "ego" eurocêntrico, ocorreu essencialmente quando Descartes exprime definitivamente o "eu penso" como a definição da ideia de pessoa no Discurso do Método, e constitui o primeiro momento histórico da concepção de Modernidade. (DUSSEL, Enrique. 1492: O encobrimento do Outro. A origem do mito da modernidade. Trad. Jaime A. Claesen. Petrópolis - RJ, Vozes, 1993, p. 15-17). 
servidão ${ }^{45}$. Para que não se afirme como utopia, os direitos humanos devem representar a reivindicação da lei à justiça, fortalecido pela certeza do sofrimento do passado e das injustiças do presente, atuando "como parasitas no corpo dos direitos, ao consumir o hospedeiro e projetar no futuro a partir de uma história jurídica um tanto insípida" ${ }^{46}$.

Todavia, dos problemas que se originaram da ideia de dignidade e moralidade a partir da modernidade e do eurocentrismo racionalista, importante asseverar que a ideia de raça desponta como categoria mental da modernidade, a qual pode ter se originado na Conquista da América "como referência às diferenças fenotípicas entre conquistadores e conquistados, mas o que importa é que desde muito cedo foi construída como referência a supostas estruturas biológicas diferenciais entre esses grupos" ${ }^{\text {"47 }}$. Assim, termos que inicialmente se referiam à procedência geográfica das pessoas passaram a significar a sua identidade, numa conotação racial, o que encontrou fundamento, logicamente, na definição de pessoa definida por Descartes no Discurso do Método como sendo o sujeito do penso, logo existo. Todos os povos originários da América, independentemente da tribo ou cultura a que pertenciam antes da conquista ibérica, passaram a ser considerados "índios", assim como aconteceu com todos os povos traficados da África para o desenvolvimento da matriz colonial de poder na América, que passaram a se chamar "negros" e, da mesma forma, todos os colonizadores passaram a ser "brancos" ou "europeus". As relações sociais configuradas a partir da conquista foram de dominação, respaldadas pelo discurso legitimador das diferenças ou superioridades subjetivas raciais.

45 COSTAS DOUZINAS. O fim dos direitos humanos. São Leopoldo: Editora Unisinos, 2009, p. 190.

46 COSTAS DOUZINAS. [2009]. Op cit., p. 383.

47 QUIJANO, Anibal. Colonialidade do poder, eurocentrismo e América Latina. In: LANDER, Edgardo (Org.). A colonialidade do saber: eurocentrismo e ciências sociais. Perspectivas latino-americanas. Colección Sur Sur, CLACSO, Ciudad Autónoma de Buenos Aires, Argentina. setembro 2005, p. 107. 
Tendo em vista que o colonialismo e a dominação de um povo sobre outro são anteriores à modernidade, a ideia de raça passou a justificar a relação de superioridade/inferioridade entre dominantes e dominados. Segundo Anibal Quijano, o discurso de dominação da modernidade segundo a ideia de raça:

[...] Desde então demonstrou ser o mais eficaz e durável instrumento de dominação social universal, pois dele passou a depender outro igualmente universal, no entanto mais antigo, o intersexual ou de gênero: os povos conquistados e dominados foram postos numa situação natural de inferioridade, e consequentemente também seus traços fenotípicos, bem como suas descobertas mentais e culturais. Desse modo, raça converteu-se no primeiro critério fundamental para a distribuição da população mundial nos níveis, lugares e papeis na estrutura de poder da nova sociedade. Em outras palavras, no modo básico de classificação social universal da população mundial. ${ }^{48}$

A classificação racial da população mitigou o fundamento da dignidade pela sua relação intrínseca à ideia de racionalidade, fundamento da racionalidade do sistema-mundo a partir da modernidade e da colonialidade. A primeira resistência hegemônica a partir dessa racionalidade legitimadora da dominação que se deu no contexto da conquista da América ocorreu no debate entre Guinés de Sepúlveda e Bartolomé de Las Casas acerca da legitimação das relações de dominações entre colonizadores "brancos" e colonizados "índios"; o debate entre os adversários girava em torno da pergunta que ainda perturba o mundo: quem tem o direito de intervir, quando e como? ${ }^{49}$

Os argumentos básicos ${ }^{50}$ de Sepúlveda para justificar a dominação e a luta contra os índios são argumentos que "têm sido

48 QUIJANO, Anibal. Colonialidade do poder, eurocentrismo e América Latina. In: LANDER, Edgardo (Org.). A colonialidade do saber: eurocentrismo e ciências sociais. Perspectivas latino-americanas. Colección Sur Sur, CLACSO, Ciudad Autónoma de Buenos Aires, Argentina. setembro 2005, p. 108.

49 WALLERSTEIN, Immanuel Maurice. O universalismo europeu: a retórica do poder. Trad. Beatriz Medina. São Paulo: Boitempo, 2007, p. 30-33.

50 Eram quatro: índios como povo bárbaro, incapaz de aprender, o que justifica sua dominação por outros. Em sua segunda tese, argumentava que deveriam 
usados para justificar todas as 'intervenções' subsequentes dos 'civilizados' do mundo moderno em zonas 'não-civilizadas': a barbárie dos outros, o fim de práticas que violam os valores universais, a defesa de inocentes em meio aos cruéis e a possibilidade de disseminar valores universais." ${ }^{51}$. Por outro lado, o principal argumento de Las Casas se concentrava em torno do princípio do "mal menor" frente à teoria de Sepúlveda sobre a obrigação do povo europeu em libertar os inocentes, especialmente as vítimas das cerimônias de sacrifício, etc. Para Las Casas, pecado maior era matar inocentes para punir os culpados, uma vez que toda a sua argumentação também era movida pela esperança de que os infiéis seriam convertidos e seus erros seriam perdoados, porque ignoravam Deus ${ }^{52}$. Ou seja, Las Casas sustentava que apesar da moralidade inferior da cultura indígena, não seria possível admitir e construir uma superioridade por meio da violência e da dominação de outros povos, porque isso não era cristão - derrubando o argumento de Sepúlveda com a força moral do contexto religioso.

No entanto, entende Wallerstein que o debate entre os pensadores da Escola de Salamanca no século XVI não surtiu efeito porque, no século XIX, as potências europeias voltaram a proclamar a necessidade de uma missão civilizadora no mundo colonial. E que mesmo com a emergência do período de descolonização, na metade do século XX, manteve-se o discurso da interferência; o que antes era justificado pela evangelização, depois passou a ser justificado pela "defesa dos direitos humanos". A pergunta acerca do direito de intervir persiste pertinentemente indo direto ao cerne da estrutura moral e

aceitar a dominação como punição por seus crimes contra a lei divina e natural. A terceira razão para a dominação girava em torno da necessidade de se impedir o mal (semelhança com os dias de hoje, invasão dos EUA no Iraque). A quarta compreende o argumento de que o domínio espanhol facilitava a evangelização, proporcionando mais segurança aos padres católicos. (WALLERSTEIN, Immanuel Maurice. O universalismo europeu: a retórica do poder. Trad. Beatriz Medina. São Paulo: Boitempo, 2007, p. 33-34).

51 WALLERSTEIN. [2007]. Op cit., p. 35.

52 WALLERSTEIN. [2007]. Op cit., p. 39. 
política do sistema-mundo moderno, inicialmente verificadas na missão evangelizadora e atualmente previstas nas "missões de salvação" no sentido de defesa dos direitos humanos e das recentes democracias ${ }^{53}$.

Em razão disso, a realidade do sistema-mundo moderno só pode ser explicada sob o condão do universalismo europeu como um conceito que define o conjunto de doutrinas e pontos de vista éticos que derivam do contexto europeu e ambicionam ser valores universais globais ou como tal são apresentados ${ }^{54}$. Esse universalismo é construído, evidentemente, pelas elites europeias, brancas, outrora colonizadoras, e tem a força de, ainda hoje, encobrir o Outro, num diálogo com o pensamento dusseliano, e de impossibilitar a construção de estruturas igualitárias diante do sistema capitalista que, por seu turno, obscurantiza maiores empreendimentos morais da humanidade ${ }^{55}$.

A negação do elemento indispensável à formulação do "penso, logo existo" cartesiano, o "ego conquiro" 56 consolidado em toda a sua profundidade e extensão a partir da conquista da América, representa a dimensão da corporalidade negada e silenciada. A violência da colonialidade do poder e de suas constantes rearticulações, a partir da dimensão do capitalismo enquanto sistema global, leva à necessidade, consequentemente, de se expressar um espaço conceitual e crítico

53 WALLERSTEIN, Immanuel Maurice. O universalismo europeu: a retórica do poder. Trad. Beatriz Medina. São Paulo: Boitempo, 2007, p. 59.

54 WALLERSTEIN. [2007]. Op cit., p. 59.

55 Leiam-se as considerações de Walter Mignolo e de Ramón Grosfoguel, que acreditam se tratar de tornar visíveis os aspectos invisibilizados pela colonialidade do poder global das lutas alter-mundialistas que se desenvolvem na atualidade "desde as subalternidades epistêmico-políticas diversas dos povos periferializados e colonizados pelo 'sistema-mundo europeu/euro-americano capitalista/patriarcal moderno/colonial” (MIGNOLO, Walter; GROSFOGUEL, Ramón. Intervenciones Descoloniales: una breve introducción..Tabula Rasa. Bogotá - Colômbia, jul-dez, 2008, n. 9, p. 37). O conceito de sistema-mundo pode ser também encontrado no ensaio de Ramón Grosfoguel denominado: “Actualidad del pensamiento de Aimé Cesaire: redefinición del sistema-mundo y producción de utopía desde la diferencia colonial", publicado em Aimé Cesaire, Discurso sobre el colonialismo (Ediciones Akal, 2006).

56 DUSSEL, Enrique. 1492: O encobrimento do Outro. A origem do mito da modernidade. Trad. Jaime A. Claesen. Petrópolis - RJ, Vozes, 1993. 
propício para a formação de um discurso legitimador da dignidade dos direitos humanos a partir da corporalidade e da resistência como produtos culturais.

A corporalidade identificada no discurso jurídico pode servir para subjugar ou emancipar. Por exemplo, a Lei 6.001/1973, "Estatuto do Índio", em seu artigo $1^{\circ}$, indica a pretensão de regular a situação jurídica dos índios ou silvícolas e das comunidades indígenas, com o propósito de preservar a sua cultura e integrá-los, progressiva e harmoniosamente, à comunhão nacional. ${ }^{57}$ Negava-se o direito indígena originário a uma existência alheia à hegemônica colonial que lhes foi imposta, em ato de subjugação. A intenção de incorporação só mudaria na Constituição Federal de 1988, por seu artigo 231, caput, quando foram reconhecidos aos índios sua organização social, costumes, línguas, crenças e tradições, e os direitos originários sobre as terras que tradicionalmente ocupam, ${ }^{58} \mathrm{em}$ ato de emancipação.

Dessa forma, constata-se que os elementos da fundamentação ocidental ética e filosófica dos direitos e dos direitos humanos participaram e contribuíram para o processo de encobrimento da dimensão colonial da modernidade e, consequentemente, de todas as estratégias discursivas de dominação que igualmente foram albergadas no espaço concernente à defesa dos direitos humanos na atualidade.

Segundo Joaquín Herrera Flores, os direitos humanos correspondem a um espaço por meio do qual é possível identificar uma tensão entre os direitos reconhecidos e as práticas sociais que buscam tanto seu reconhecimento positivado como outra forma de reconhecimento ou outro procedimento que garanta algo que se constitui como interior e, simultaneamente, exterior a tais normas.

57 BRASIL. Lei n. 6001 de 19 de dezembro de 1973. Dispõe sobre o Estatuto do Índio. Disponível em: <http://www.planalto.gov.br/ccivil_03/leis/L6001.htm>. Acesso em 24 de outubro de 2019.

58 BRASIL. Constituição (1988). Constituição da República Federativa do Brasil de 1988. Disponível em: <http://www.planalto.gov.br/ccivil_03/constituicao/ constituicao.htm>. Acesso em 24 de outubro de 2019. 
Interior devido ao fato de que as normas - constituições, declarações, tratados - podem influir positivamente no resultado de certos níveis de garantia ${ }^{59}$. Exterior porque reconhecem e legitimam os esforços de processos históricos de lutas sociais pela efetivação da dignidade humana.

Para Herrera Flores, é impossível que os resultados - interiores ou exteriores - da compreensão e da efetivação dos direitos humanos sejam realizados de modo neutro ou apolítico. A partir dessa caracterização, rompe-se com a matriz metafísica que direciona em grande parte a teoria jurídica e o discurso hegemônico dos direitos humanos, considerando-os como ideais prévios à ação social. Por exemplo, o direito humano à vida não é exercido da mesma maneira por pessoas negras (pretos e pardos) e não-negras (brancos, amarelos e indígenas) no Brasil. A Constituição Federal de 1988, em seu artigo 5², caput, informa que todos são iguais perante a lei, sem distinção de qualquer natureza, garantindo-se aos brasileiros e aos estrangeiros residentes no País a inviolabilidade do direito à vida. Entretanto, a herança colonial escravocrata brasileira implica em uma diferença substancial entre os números de assassinatos de acordo com a cor da pele. Em 2018, as pessoas negras foram assassinadas em uma proporção de 40,2 por cem mil habitantes, enquanto as pessoas não negras foram assassinadas em uma proporção de 16 por cem mil habitantes. ${ }^{60}$

Ao situar a dimensão política dos direitos humanos, Joaquín Herrera Flores faz uma critica da concepção geral restrita do político, noção que agrega o conceito da corporalidade, o qual nega a compreensão dos ideais contidos na concepção de direitos humanos enquanto produtos dados de antemão e sem qualquer relação com os

59 HERRERA FLORES, Joaquín. A (re)invenção dos direitos humanos. Fundação Boiteaux: Florianópolis, 2009, p. 34.

60 CERQUEIRA, Daniel Coordenador et al. Atlas da violência 2018. Ipea e FBSP, 2018. Disponível em: <http:// repositorio.ipea.gov.br/bitstream/11058/8398/1/ Atlas\%20da\%20viol\%c3\%aancia 2018.pdf>. Acesso em 24 de outubro de 2019. 
conflitos sociais ${ }^{61}$. É o corporal que faz com que o ser humano necessite da comunidade para satisfazer as suas exigências pessoais, ideia que desconstrói radicalmente o núcleo da ideologia liberal dos direitos humanos, especialmente porque as liberdades individuais assim situadas não necessitariam de contexto algum para serem consideradas direitos de plena satisfação.

A integralidade dos direitos humanos exige que se pense e teorize a partir da corporalidade, das condições materiais e históricas que determinaram e ainda determinam a construção do pensamento social, jurídico e político. Os elementos do impuro, do corporal, aqui representam as noções trazidas a partir do pensamento descolonial e, igualmente, das proposições de seus teóricos norteadores do passado. Pensar os direitos humanos a partir da colonialidade do poder, nesse sentido, exige o entendimento dessa dimensão que mereceu tamanho destaque para a teoria crítica dos direitos humanos proposta por autores como Herrera Flores e Costas Douzinas.

Com Herrera Flores, é possível analisar que as lutas por direitos humanos são responsáveis pela sua real universalização como base ética e jurídica de práticas sociais voltadas à vivência da dignidade humana, análise que prescinde de um estudo do locus valorativo em que se situa a dignidade e a própria implementação prática, mais ou menos possível, dos direitos humanos. Somente a partir da compreensão do sistema de valores que possibilita, em maior ou menor medida, a realização dos direitos humanos é que se mostra possível se aproximar desse discurso e da ideia de dignidade ${ }^{62}$.

61 HERRERA FLORES, Joaquín. A (re)invenção dos direitos humanos. Fundação Boiteaux: Florianópolis, 2009, p. 79.

62 HERRERA FLORES, Joaquín. A (re)invenção dos direitos humanos. Fundação Boiteaux: Florianópolis, 2009, p. 51. 


\section{Conclusão}

Não obstante seja possível visualizar que Kant considerasse a pessoa ou o sujeito da moralidade muito além do que a mera racionalidade, o filósofo defende que a personalidade se caracteriza pela moralidade dos seres racionais. Isso consiste na submissão pela própria condição de seres autônomos, sendo a autonomia a capacidade de agir moralmente e, portanto, gozar de direitos e da imputação de responsabilidades; assim, diferencia-se a pessoa, ser moral, do ser humano, ser corporal. De acordo com tal distinção, é possível fundamentar o discurso de legitimação de opressões contra sujeitos e direitos, destacando-se a colonialidade do poder originada no colonialismo moderno e ancorada na questão da racionalidade.

Considerando que a filosofia tem o condão de explicar o conceito, a função e as consequências da racionalidade na teoria dos direitos e dos direitos humanos, buscou-se aqui estabelecer uma reconstrução teórica sobre o discurso de fundamentação da dignidade e dos direitos humanos. Com base nas contribuições kantianas à dignidade e nas críticas a tais contribuições a partir da filosofia e da própria teoria crítica dos direitos humanos, conclui-se que a concepção material e concreta de dignidade deve passar pela universalidade que atente especialmente à necessidade do que Joaquín Herrera Flores chamou de circuitos de reação cultural: o reconhecimento, o respeito, a reciprocidade, a responsabilidade e a redistribuição $0^{63}$, uma vez que pensar em direitos humanos devem necessariamente passar por um exame de autoconsciência, a fim de que as pessoas saibam incluir ou reconhecer a dignidade como valor, princípio e fundamento básico de qualquer direito humano, independentemente de diferenças culturais e em respeito às legislações positivadas nesse sentido.

O problema da fundamentação dos direitos humanos assume primordial importância na medida em que serve para legitimar ações

63 HERRERA FLORES. [2009]. Op cit., p. 117. 
práticas em relação a esses direitos: serve para demonstrar a falta de reconhecimento fático dos direitos humanos e, consequentemente, responder ao problema do seu recorrente desrespeito, não obstante estes sejam largamente positivados na esfera jurídica, enfatizados nos discursos políticos e reivindicados pelas sociedades. A fundamentação dos direitos humanos, mais do que basilar à sua concepção teórica, corresponde ao corolário na busca pela sua consolidação.

Consideradas as insuficiências do discurso hegemônico dos direitos humanos, entende-se que sua fundamentação passa por uma baliza simultaneamente ética e jurídica, exigindo pleno reconhecimento, proteção e garantia de direitos, conformando-os às exigências máximas da dignidade humana. De maneira que os direitos humanos se pressupõem destinados à pessoa moral, categoria que vai além do caráter circunstancial de pertencimento à espécie humana, podem ser considerados uma categoria axiológica de direitos, aportada a princípios morais inerentes a qualquer ser humano e em qualquer condição de vida.

Os já verificados problemas nas proposições tradicionais de fundamentação da dignidade e dos direitos humanos conduzem à necessidade de ampliação da esfera de compreensão e conceituação desses direitos, compreendidos enquanto espaços de luta pela efetivação da dignidade humana que, por isso mesmo, devem se abrir às possibilidades teóricas de fundamentação críticas, capazes de explorar os limites da racionalidade moderna ocidental, tal qual se apresenta a perspectiva descolonial e a teoria crítica dos direitos humanos.

\section{Referências}

BARRETTO, Vicente de Paulo. Multiculturalismo e direitos humanos: um conflito insolúvel? In: BALDI, César Augusto (Org.). Direitos humanos na sociedade cosmopolita. Rio de Janeiro: Renovar, 2004, p. 279-308. 
BARRETTO, Vicente de Paulo. O Fetiche dos Direitos Humanos e outros Temas. 2. ed. Porto Alegre: Livraria do Advogado, 2013.

BATTESTIN, Cláudia; GHIGGI, Gomercindo. O princípio responsabilidade de Hans Jonas: um princípio ético para os novos tempos. Thaumazein, Santa Maria, n. 6, p. 69-85, out. 2010

BRAGATO, Fernanda Frizzo. Positivação e efetividade dos direitos humanos. Estudos Jurídicos. Universidade do Vale do Rio dos Sinos. São Leopoldo, v. 40, n. 2, p. 66-71, jul./dez. 2007.

BRASIL. Lei n. 6001 de 19 de dezembro de 1973. Dispõe sobre o Estatuto do Índio. Disponível em: http://www.planalto.gov.br/ ccivil_03/leis/L6001.htm. Acesso em: 24 out. 2019.

BRASIL. Constituição (1988). Constituição da República Federativa do Brasil de 1988. Disponível em: http://www.planalto.gov.br/ ccivil_03/constituicao/constituicao.htm. Acesso em: 24 out. 2019.

CERQUEIRA, Daniel Coordenador et al. Atlas da violência 2018. Ipea e FBSP, 2018. Disponível em: http:// repositorio.ipea.gov.br/ bitstream/11058/8398/1/Atlas\%20da\%20viol\%c3\%aancia_2018.pdf. Acesso em: 24 out. 2019.

DUSSEL, Enrique. 1492: O encobrimento do Outro. A origem do mito da modernidade. Trad. Jaime A. Claesen. Petrópolis: Vozes, 1993.

HABERMAS, Jürgen. A ética da discussão e a questão da verdade. São Paulo: Martins Fontes, 2007.

HABERMAS, Jürgen. Lutas pelo Reconhecimento no Estado Constitucional Democrático. In: TAYLOR, Charles. Multiculturalismo: examinando a política de reconhecimento. Lisboa: Instituto Piaget, 1994, p. 125-164.

HERRERA FLORES, Joaquín. A (re)invenção dos direitos humanos. Fundação Boiteaux: Florianópolis, 2009.

HÖFFE, Otfried. O imperativo categórico do Direito: uma interpretação da "Introdução à Doutrina do Direito". Studia Kantiana, v. 1, 1998. p. 203-236. 
JONAS, Hans. O Princípio Responsabilidade. Ensaio de uma ética para a civilização tecnológica. Trad. Marijane Lisboa e Luiz Barros Montez. Rio de Janeiro: Contraponto, 2006.

JUNGES, José Roque. A concepção kantiana de dignidade humana. Estudos Jurídicos. Universidade do Vale do Rio dos Sinos. São Leopoldo, v. 40, jul-dez 2007, n. 2, p. 84-87.

KANT, Immanuel. Doutrina do Direito. São Paulo: Ícone, 1993.

KANT, Immanuel. Fundamentação à metafísica dos costumes. São Paulo: Companhia Editora Nacional, 1964.

LANDER, Edgardo. Ciências sociais: saberes coloniais e eurocêntricos. In: LANDER, Edgardo (Org.). A colonialidade do saber: eurocentrismo e ciências sociais. Perspectivas latinoamericanas. Buenos Aires: Colección Sur Sur, CLACSO, setembro 2005, p. 8-23.

LEVINAS, Emmanuel. Totalidade e Infinito. Lisboa: Edições 70, 1980 .

MIGNOLO, Walter; GROSFOGUEL, Ramón. Intervenciones Descoloniales: una breve introducción. Tabula Rasa. Bogotá - Colômbia, jul-dez, 2008, n. 9, p. 29-37.

QUIJANO, Anibal. Colonialidade do poder, eurocentrismo e América Latina. In: LANDER, Edgardo (Org.). A colonialidade do saber: eurocentrismo e ciências sociais. Perspectivas latino-americanas. Colección Sur Sur, CLACSO, Ciudad Autónoma de Buenos Aires, Argentina., setembro 2005. p. 227-278.

RORTY, Richard. Human rights, rationality and sentimentality. In: HEYDEN, Patrick. The politics of human rights. St. Paul, MN: Paragon House, 2001. p. 67-83.

WALLERSTEIN, Immanuel Maurice. O universalismo europeu: a retórica do poder. Trad. Beatriz Medina. São Paulo: Boitempo, 2007. 